\title{
Synthesis and Characterization of New Soluble Poly (Arylene Ether Ketone)s
}

Nasrin Paya ${ }^{1}$, Mehdi Ghaffari ${ }^{2}$ and Hossein Mighani ${ }^{{ }^{*}}$

${ }^{1}$ Polymer Laboratory, Department of Chemistry, Golestan University, P.O. Box 155, Gorgan, Iran

${ }^{2}$ Polymer Laboratory, Department of Polymer Engineering, Golestan University, P.O. Box 155, Gorgan, Iran

"Corresponding author: Hossein Mighani, Polymer Laboratory, Department of Chemistry, Golestan University, P.O. Box 155, Gorgan, Iran, Tel: +981732245964; E-mail: h.mighani@gu.ac.ir

Received date: March 05, 2018; Accepted date: March 15, 2018; Published date: March 27, 2018

Copyright: @ 2018 Paya N, et al. This is an open-access article distributed under the terms of the Creative Commons Attribution License, which permits unrestricted use, distribution, and reproduction in any medium, provided the original author and source are credited.

\begin{abstract}
A novel bisfluoro monomer was synthesized in two steps:

1) 9-ethylcarbazoleobtained obtained from $9 \mathrm{H}$-Carbazole and 1-bromoethane, and

2) a new 3, 6-bis-4-fluorobenzoyl-9-ethylcarbazole monomer was obtained from 9-ethylcarbazole and 4fluorobenzoylchloride; it was then used to prepare novel Poly (Arylene Ether Ketone)s (PAEKs). FTIR and ${ }^{1}$ HNMR methods were used to characterize the synthesized monomers and polymers. Further, solubility tests showed that PAEKs were generally soluble in a wide range of solvents including Dimethyl Acetamide (DMAc), $\mathrm{N}$ Methylpyrrolidone (NMP), Dimethyl Sulfoxide (DMSO) and $\mathrm{H}_{2} \mathrm{SO}_{4}$. Thermo Gravimetric Analysis (TGA) and Differential Scanning Calorimetry (DSC) indicate that the synthesized PAEKs showed only $10 \%$ weight loss in air up to $410^{\circ} \mathrm{C}$ and were essentially amorphous.
\end{abstract}

Keywords: Carbazole; Polycondenzation; Poly (arylene ether ketone); Solubility; Thermal properties
Abbreviations:
PAEKs: Poly (Arylene Ether Ketone)s; DMAc: Dimethyl Acetamide; NMP: N-Methylpyrrolidone; DMSO: Dimethyl Sulfoxide; TGA: Thermo Gravimetric Analysis; DSC: Differential Scanning Calorimetry.

\section{Introduction}
Poly (arylene ether)s form a major class of high performance polymeric materials with excellent thermal and mechanical properties [1-3]. These polymers consist of aromatic rings and ether linkages. Amongst various methods for synthesis of poly (arylene ether)s, one method is widely used: nucleophilic displacement of an activated dihalo and dinitro compound with activated bisphenoxide salt at high temperature [4-6]. Despite the necessity to activate the leaving groups by an electron withdrawing group (e.g., sulfone, ketone or imide groups) at the para-position, Johnson, demonstrated that the presence of these groups results in synthesis of high molecular weight poly ethers [4]. Within aromatic poly (arylene ether)s, PAEK pose a quality performance in thermo-oxidative, electrical and chemical resistance properties [7-9]. This makes them suitable candidates as advanced materials in aerospace, electronics and nuclear fields industry [10-15]. Despite different approaches in synthesis of these polymers, they are mainly synthesized using insolation by the nucleophilic aromatic substitution $\left(\mathrm{S}_{\mathrm{N}} \mathrm{Ar}\right)$ between bisphenols and aromatic bis-halide salt high reaction temperatures (typically $>150^{\circ} \mathrm{C}$ ) and in the presence of weak bases such as $\mathrm{K}_{2} \mathrm{CO}_{3}$ and $\mathrm{Na}_{2} \mathrm{CO}_{3}[2,16]$. Conducting polymers containing conjugated double bonds along the backbone due to their

flexibility, ease of fabrication and lightness of weight possesses great superiority over the inorganic semiconductors [17]. Due to these advantages, they have been investigated as the materials of electronics, optoelectronics, and photonics. These polymers are also potential candidates for a wide spectrum of commercial applications ranging from catalysts for photo-electrochemical processes, electrode materials, microelectronic devices, and organic batteries to electro chromic display devices $[17,18]$. $9 \mathrm{H}$-carbazole is a heterocyclic compound with photo conducting properties and high electrondonating characteristics that is used in the synthesis of poly condensation or polymerization polymers. In addition to interesting electro-optical and photochemical properties, this compound donates high thermal stability to polymer due to its conjugated structure [18]. 9H-carbazole can be easily functionalized on the 3,6-, [19] 2,7-, [20] or $\mathrm{N}$-positions, [21] it is covalently linked into polymeric systems, both in the main chain as building blocks [22] and side-chain as pendant group [23].

In the present study, we synthesize new PAEKs with improved thermal properties. This procedure consists of three major steps:

1) 9-ethylcarbazole is derived via $\mathrm{N}$-alkylation onto $9 \mathrm{H}$-carbazole.

2) Friedel-Crafts Acylation on 3, 6-position of 9-ethylcarbazole results in the new monomer, bis-halide.

3) The polymer is produced by poly-condensation between the new bis-halide monomer and three aromatic diols (resorcinol, hydroquinone and naphthalene diols).

Subsequently, the synthesized polymer is analyzed in terms of its thermal and also solubility properties. 


\section{Experimental}

\section{Materials and instruments}

9H-Carbazole, ethylbromide, 4-fluorobenzoyl chloride, 18-crown-6 and all other chemicals were purchased from Fluka (Switzerland). ${ }^{1} \mathrm{HNMR}$ spectra were recorded on a Bruker advance DRX $500 \mathrm{MHz}$ instrument, using DMSO- $\mathrm{d}_{6}$ and $\mathrm{CdCl}_{3}$ as solvent and tetramethylsilane as an internal standard. FTIR spectra were recorded on a Bruker, Vector 22 spectrometer, using $\mathrm{KBr}$ pellets. TGA under air atmosphere and heating rate of $20 \mathrm{~K} / \mathrm{min}$ in the range of $43-650^{\circ} \mathrm{C}$ using TGA-Q500 TA and DSC from room temperature to $280^{\circ} \mathrm{C}$ at 10 $\mathrm{K} /$ min under $\mathrm{N}_{2}$ atmosphere using DSC-Discovery TA were performed. Inherent viscosity $\left(\eta_{\text {inh }}=\ln \eta_{\text {rel }} / \mathrm{c}\right)$ of polymers was determined for solutions of $0.1,0.2$ and $0.5 \mathrm{~g} / \mathrm{dl}$ in DMAc at $25^{\circ} \mathrm{C}$ using an Ubbelohde viscometer.

\section{Synthesis of 9-ethylcarbazole}

Inside a $250 \mathrm{~mL}$ two-neck round-bottom flask equipped with a magnetic stirrer bar, 9H-Carbazole $(20 \mathrm{mmol}), \mathrm{KOH}(30 \mathrm{mmol})$ and 18-Crown-6 (20 mg as phase transfer catalysis) were added to $40 \mathrm{ml}$ of toluene and refluxed for $30 \mathrm{~min}$. The solution of ethylbromide (30 mmol) compound was gradually added into $20 \mathrm{ml}$ of toluene and then into the reaction mixture (following Koyuncu procedure [24]). The mixture was stirred at $110^{\circ} \mathrm{C}$ for $6 \mathrm{~h}$ and then cooled to the room temperature. Then, the reaction mixture was poured into $150 \mathrm{ml}$ of ethanol and stripped off by a rotary evaporator. The product was recrystallized from methanol and dried in vacuum desiccators. The reaction yield was estimated to be about $93 \%$.

FTIR $\left(\mathrm{cm}^{-1}\right)$ : (aromatic C-H stretching) 3035.81; (aliphatic C-H stretching) 2857.48; (- $\mathrm{CH}_{2}$ stretching) 2917.36; $\left(-\mathrm{CH}_{3}\right.$ stretching) 2964.77; (C=C ring stretching) 1564; (aliphatic C-N) 1092.08; (aromatic C-N) 1296.67; (aromatic C-H bend out of plane) 682.06-714.15.

\section{Synthesis of monomer (3, 6-bis-4-fluorobenzoyl-9- ethylcarbazole)}

Inside a $250 \mathrm{ml}$ three-neck round-bottom flask equipped with a magnetic stirrer bar, a Nitrogen inlet, and an acid trap, $0.39 \mathrm{gr}$ (2 mmol) 9-ethylcarbazole, $0.66 \mathrm{gr}(5 \mathrm{mmol})$ aluminum chloride and 50 $\mathrm{ml}$ dichloromethane were charged. The temperature of the reaction mixture was maintained at $-5^{\circ} \mathrm{C}$ and $0.6 \mathrm{ml}(5 \mathrm{mmol})$ 4-Fluorobenzoyl chloride was added drop-wise (following Ghaemy procedure [25]). After complete addition, the medium was stirred for $2 \mathrm{~h}$ at $0^{\circ} \mathrm{C}$ and for two more hours at room temperature. Upon completion of the reaction (as witnessed by TLC test), the mixture was poured into water and extracted with ethyl acetate. The organic layer was concentrated under reduced pressure and dried at $70^{\circ} \mathrm{C}$ under vacuum. The yield of the viscous greenish liquid was 0.7 gr (80\%).

FTIR $\left(\mathrm{cm}^{-1}\right)$ : (aromatic C-H stretching) 3045.12; (aliphatic C-H stretching) 2843.42; (- $\mathrm{CH}_{2}$ stretching) 2919.55; $\left(-\mathrm{CH}_{3}\right.$ stretching) 2963.04; (C=O stretching) 1657; (C-F stretching) 1263.63; ( $\mathrm{C}=\mathrm{C}$ ring stretching) 1573.41; (aliphatic C-N) 1096; (aromatic C-N) 1299; (aromatic C-H bend out of plane) 889.86- 815.62.

${ }^{1} \mathrm{HNMR}\left(500 \mathrm{MHz}, \mathrm{CdCl}_{3}, \delta\right.$ in $\left.\mathrm{ppm}\right): 1.31-1.52(\mathrm{t}, 3 \mathrm{H}, \mathrm{CH})$, 4.44-4.45 (q, 2H, CH), 7.55-7.56 (m, 2H, Ar-H),7.92-7.94 (t, 4H, ArH), 8.03-8.09 (d, 2H, Ar-H), 8.15-8.18(t, 4H, Ar-H), 8.63 (s, 2H, Ar-H).

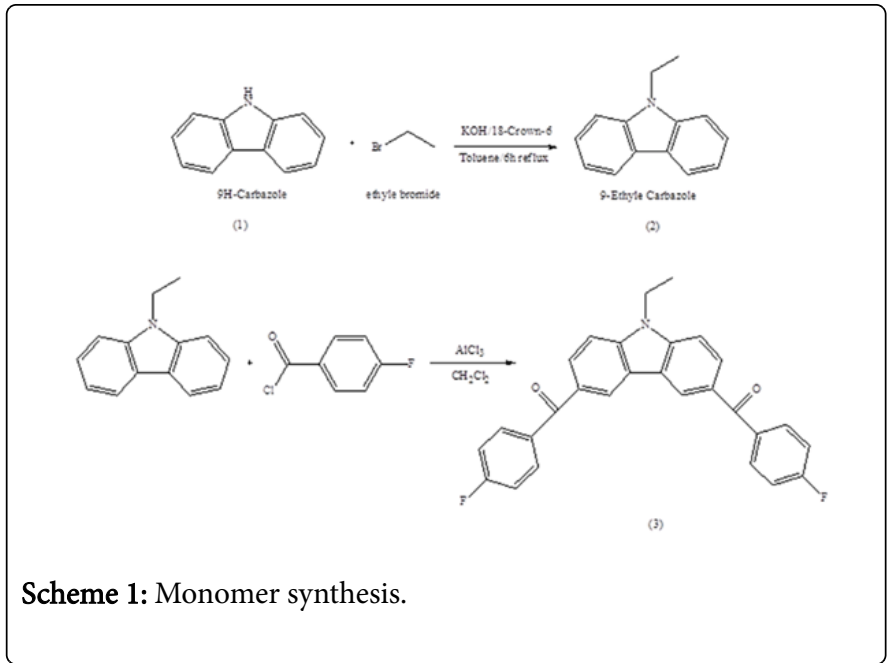

\section{Synthesis of polymer}

According to the reported procedure in the literature, [26] polymerization reactions were carried out in a $50 \mathrm{ml}$, three-neck round-bottom flask equipped with a Nitrogen inlet, a stirrer bar, and a Dean-Stark trap fitted with condenser. The reactions were conducted under constant flow of Nitrogen. A representative polymerization procedure is as follows: the flask was charged with equimolar amounts of 3, 6-bis-4-fluorobenzoyl-9-ethylcarbazole and diol (2 mmol each), $\mathrm{K}_{2} \mathrm{CO}_{3}(4.2 \mathrm{mmol})$, NMP $(20 \mathrm{ml})$ and toluene $(40 \mathrm{ml})$. The mixture was then heated to reflux $\left(140-150^{\circ} \mathrm{C}\right.$, oil bath temperature) for $2-3 \mathrm{~h}$ to remove the water azeotropically with toluene. After removal of the toluene from the Dean-Stark trap, the reaction temperature was increased to $180^{\circ} \mathrm{C}$ and maintained for another $6 \mathrm{~h}$. After cooling to room temperature, the polymer was precipitated from about $500 \mathrm{ml}$ of methanol containing $10 \mathrm{ml}$ of $\mathrm{HCl}$. Fibrous solids were isolated. These products were washed several times in boiling distilled water to remove any inorganic impurities followed by methanol and dried under vacuum at $65^{\circ} \mathrm{C}$ for overnight.

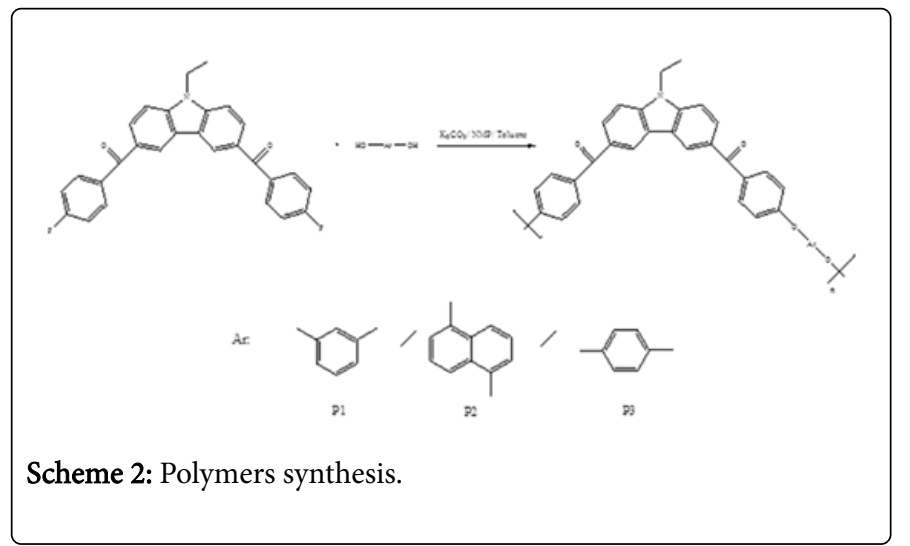

FTIR $\left(\mathrm{cm}^{-1}\right)$ : P1: (aromatic C-H stretching) 3048.10; (aromatic CN) 1280.09; (C=C ring stretching) 1562.81; (aliphatic C-N) 1092.17; (C=O stretching) 1658.69; (C-O-C stretching) 1229.66.

P2: (aromatic C-H stretching) 3043.92; (aromatic C-N) 1278.60; $(\mathrm{C}=\mathrm{C}$ ring stretching) 1565.93; (aliphatic $\mathrm{C}-\mathrm{N})$ 1093.63; $\quad(\mathrm{C}=\mathrm{O}$ stretching) 1658.70; (C-O-C stretching) 1214.30. 
P3: (aromatic C-H stretching) 3044.98; (aromatic C-N) 1280.52; $(\mathrm{C}=\mathrm{C}$ ring stretching) 1566.78; (aliphatic $\mathrm{C}-\mathrm{N})$ 1095.04; $\quad(\mathrm{C}=\mathrm{O}$ stretching) 1658.73; (C-O-C stretching) 1158, 1197.

${ }^{1} \mathrm{HNMR}\left(500 \mathrm{MHz}, \mathrm{DMSO}-\mathrm{d}_{6}, \delta\right.$ in ppm):

P1: 1.18-1.34 (t, 3H, CH), 4.5 (q, 2H, CH), 7.20-8.74(Ar-H).

\section{Results and Discussion}

\section{Monomer synthesis and characterization}

The new bisfluoro monomer containing 9-ethylcarbazole as internal unit and 4-fluorobenzoyl chloride as terminal units was synthesized in two steps. From a synthetic standpoint, there are generally three distinct methods for incorporating carbazole units into a polymeric material: polymerization with the carbazole's 1) 3, 6-positions, [27-30] 2) 2,7-positions [31] or 3) 9-position. Since it is desirable that 4-fluoro benzoyl chloride do not react with the 9-position, at first 9-position was functionalized to lose its reactivity. This step consists of aliphatic nucleophilic substitution reaction. Yellowish needle-like 9ethylcarbazole crystals obtained from Friedel-Crafts alkylation reaction between $9 \mathrm{H}$-carbazole and 1-bromoethane in the presence of $\mathrm{KOH}$ and 18-crown-6 phase transfer catalyst in toluene solvent. In order to purify the product, recrystallization by methanol was done (Scheme 1). The production of 9-ethylcarbazole was confirmed by FTIR (Figure 1).

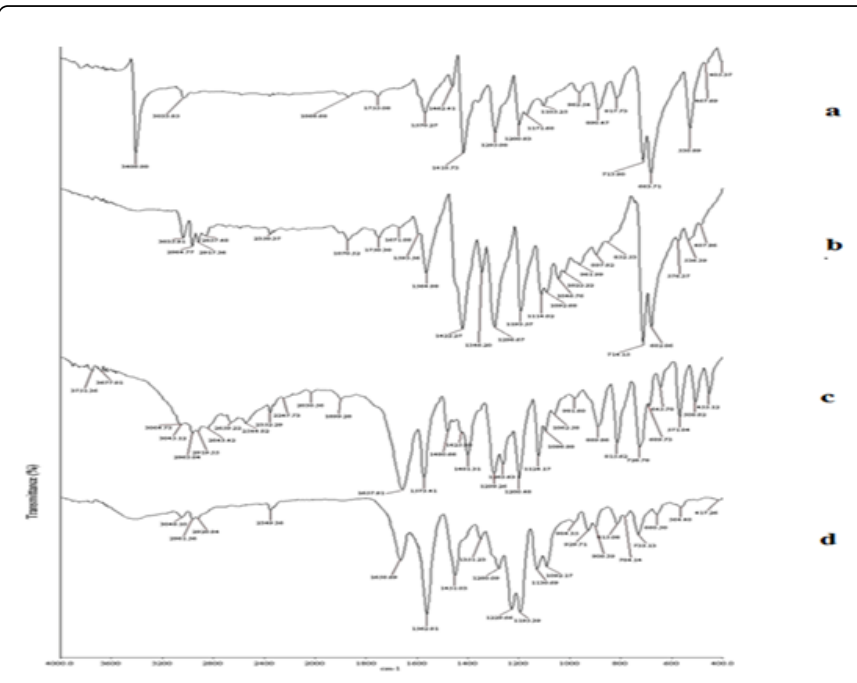

Figure 1: FTIR spectra of (a) 9H-Carbazole, (b) 9-ethylcarbazole, (c) difluoride monomer and (d) P1.

Carbazole as a result of its N-H bond shows an absorption peak at $3408 \mathrm{~cm}^{-1}$. This peak has been replaced by absorption peaks at 1092 and $1114 \mathrm{~cm}^{-1}$ which attribute to aliphatic C-N bond. Also, some absorption peaks are detectible at 2917, 2964 and $2857 \mathrm{~cm}^{-1}$ which attribute to $\mathrm{CH}_{2}, \mathrm{CH}_{3}$ and aliphatic $\mathrm{C}-\mathrm{H}$, respectively. In the next step, Friedel-Crafts acylation reaction was performed between 9ethylcarbazole and 4-fluorobenzoyl chloridein the presence of aluminum chloride catalyst in dichloromethane solvent (Scheme 1); the reaction product was then separated using ethyl acetate. The reason behind situation of 4-fluorobenzoyl chloride on the 3,6- position of 9ethylcarbazole can be explained in the following way: 9-ethylcarbazole can react at 3,6- or 2-7- positions, however from organic chemistry viewpoint preparation of 2,7-dihalosubstituted carbazoles is not as straightforward as the synthesis of 3,6-substituted samples [32]. In addition, reaction between 9-ethylcarbazole and 4-fluorobenzoyl chloride is an electrophilic aromatic substitution and meta position of amino group of carbazole, i.e., 2,7- positions, cannot be functionalized directly by this method [32]. Therefore, 4-fluorobenzoyl chloride situated on the 3,6- position of 9-ethylcarbazole. The chemical structure of monomer has been confirmed using FTIR and NMR spectra. FTIR spectra of monomer has absorption peaks of $\mathrm{C}=\mathrm{O}$ and $\mathrm{C}-\mathrm{F}$ at 1657 and $1263 \mathrm{~cm}^{-1}$, respectively. In the ${ }^{1} \mathrm{HNMR}$ spectra of monomer (Figure 2), associated signals of $\mathrm{CH}_{3}$ and $\mathrm{CH}_{2}$ groups are detectible in 1.31-1.52 and 4.44-4.45 ppm. More chemical shift of $\mathrm{CH}_{2}$ results from the higher electronegativity of Nitrogen atom that has been connected to $\mathrm{CH}_{2}$ in this sample.



Figure 2: ${ }^{1} \mathrm{HNMR}$ spectra of (a) difluoride monomer and (b) P2.

Since there is no proton in the vicinity of proton of carbon 1, its signal has been appeared as singlet, on the other hand signal related to the proton of carbon 5 as a result of presence of protons of alkyl group and also carbon 4 appears as multiple.

\section{Polymer synthesis and characterization}

In the polymerization step, new difluoride monomer in the presence of $\mathrm{K}_{2} \mathrm{CO}_{3}$ and NMP solvent in a poly-condensation process reacted with 3 types of bisphenol to production of 3 new PAEKs (Scheme 2). At the primary steps of reaction, toluene was used to eliminate zeotropic water that had being produced as a side-product during reaction. A Dean-Stark apparatus was implemented to remove this water. After about 2 hours of reaction, toluene was removed from reaction medium and creation of bisphenolate was completed. Then, reaction temperature was increased to about $180^{\circ} \mathrm{C}$ to production of polymer in 4-6 hours. This reaction is an aromatic nucleophilic substitution reaction. Since, aromatic nucleophilic substitution reaction needs the presence of a strong nucleophilic group, [33] $\mathrm{K}_{2} \mathrm{CO}_{3}$ was used in order to convert bisphenol to the strong nucleophilic component of bisphenolate [34]. The reaction led to production of the ether, is named as Williamson synthesis [33]. Nucleophilic substitution 
Page 4 of 6

of aryl halides is rather hard to occur; however, presence of $\mathrm{C}=\mathrm{O}$ group in para and Ortho position relative to halogen, leads to easy reaction of these components [33]. Intrinsic viscosity of synthesized PAEKs was measured by preparation of a $0.1 \% \mathrm{w} / \mathrm{v}$ solution of these polymers in dimethylacetamide. The measured intrinsic viscosities of all the synthesized polymers were in the range of $0.33-0.54 \mathrm{dl} / \mathrm{gr}$. Furthermore, the structure of synthesized polymers was analyzed and confirmed by FTIR and NMR spectroscopy techniques. Disappearance of $-\mathrm{OH}$ and $\mathrm{C}-\mathrm{F}$ peaks in the ranges of 3500-3650 and $1263 \mathrm{~cm}^{-1}$, respectively, confirms the production of polymer. Also, stretching absorption peak of C-O-C at $1229 \mathrm{~cm}^{-1}$ affirms the formation of etheric bonds. In ${ }^{1} \mathrm{HNMR}$ spectra, signals of 1.34, 4.5 and 7.2-8.7 ppm associate with $\mathrm{CH}_{3}, \mathrm{CH}_{2}$ and protons of aromatic groups, respectively.

\section{Viscosity and molecular weight calculations}

Viscosity measurement with the purpose of molecular weight determination of synthesized PAEKs was performed using an
Ubbelhode viscometer. Solutions of synthesized polymers in DMAc solvent at the room temperature of $25^{\circ} \mathrm{C}$ and at 3 different concentrations of polymers were prepared. Then the passing time of prepared solutions between two signs of viscometer $(t)$ along with the passing time for pure solvent $\left(\mathrm{t}_{0}\right)$ were recorded and tabulated in Table 1. Using the following equation (Equation 1) inherent viscosity for each sample was calculated.

\section{$\eta_{\text {inh }}=\ln \left(\mathrm{t} / \mathrm{t}_{0}\right) / \mathrm{C}($ Equation 1$)$}

\section{Where, $\mathrm{C}=$ concentration}

Also, by extrapolation of the inherent viscosity values to the zero concentration of polymer, intrinsic viscosity values were achieved (Table 1).

\begin{tabular}{|c|c|c|c|c|c|c|c|c|c|c|}
\hline \multirow[b]{2}{*}{ Concentration (g/dl) } & \multirow{2}{*}{$\begin{array}{l}\text { DMAc } \\
-\end{array}$} & \multicolumn{3}{|l|}{ P1 } & \multicolumn{3}{|l|}{ P2 } & \multicolumn{3}{|l|}{ P3 } \\
\hline & & 0.1 & 0.2 & 0.5 & 0.1 & 0.2 & 0.5 & 0.1 & 0.2 & 0.5 \\
\hline Passing time (s) & 17.34 & 17.91 & 18.01 & 18.23 & 18.28 & 18.47 & 19.15 & 17.99 & 18.08 & 18.36 \\
\hline$\eta_{\text {inh }}(\mathrm{dl} / \mathrm{g})$ & - & 0.32 & 0.18 & 0.1 & 0.53 & 0.31 & 0.19 & 0.36 & 0.2 & 0.11 \\
\hline$\eta_{\text {intrinsic }}(\mathrm{d} l / \mathrm{g})$ & - & \multicolumn{3}{|l|}{0.33} & \multicolumn{3}{|l|}{0.54} & \multicolumn{3}{|l|}{0.37} \\
\hline Molecular weight & - & \multicolumn{3}{|l|}{14900} & \multicolumn{3}{|l|}{31800} & \multicolumn{3}{|l|}{17750} \\
\hline
\end{tabular}

Table 1: Inherent viscosity, intrinsic viscosity and molecular weight of synthesized PAEKs.

Finally, using Mark-Houwink equation (Equation 2) and setting a and $\mathrm{b}$ constants for PAEK equal to $6.4 \times 10^{-4}$ and 0.65 [35], respectively, the molecular weights of synthesized polymers were calculated. As it is seen in Table 1, molecular weight of P2 is higher than other polymers.

$[\eta]_{\mathrm{PAEK}}=6.4 \times 10^{-4} \mathrm{M}^{0.65}($ Equation 2$)$

\section{Solubility properties}

Conventional PAEKs without side groups could not be dissolved in most known organic solvents [36] while, as it is seen in Table 2, the novel synthesized PAEKs are soluble or partially soluble in the most aprotic polar (DMF, DMAc, NMP, THF, DMSO, etc.) solvents and also in the concentrated sulfuric acid $\left(\mathrm{H}_{2} \mathrm{SO}_{4}\right)$. It is well known that the introduction of flexible alkyl side chain attached to Nitrogen atom of the bisfluoro monomer has a positive effect on the polymer solubility; while, this effect is reduced in bisphenol containing two aromatic fused rings. In the present case, it is seen that P2 consisting of bisphenol 1, 5naphthalenediol monomer, owns less solubility in comparison with P1 and P3. In addition, the presence of 3, 6-disubstituted carbazole induces a bent conformation for polymer chain with benefits on polymer solubility $[37,38]$.

\begin{tabular}{|l|l|l|l|l|l|l|l|l|l|l|l|}
\hline & DMSO & NMP & DMF & THF & DMAc & DCM & $\mathrm{H}_{2} \mathbf{S O}_{4}$ & $\mathrm{CHCl}_{3}$ & $\mathrm{MeOH}$ & EtOH & Acetone \\
\hline $\mathrm{P} 1$ & + & + & + & + & + & - & + & \pm & - & - & - \\
\hline $\mathrm{P} 2$ & \pm & + & \pm & \pm & + & - & + & \pm & - & - & - \\
\hline $\mathrm{P} 3$ & + & + & + & + & + & - & + & \pm & - & - & - \\
\hline
\end{tabular}

Table 2: Solubility properties of synthesized PAEKs.

\section{Thermal properties}

TGA thermograms of synthesized polymers have been demonstrated in Figure 3 and the values of T5, T10, T25 and T50, corresponding to weight losses of $5 \%, 10 \%, 25 \%$ and $50 \%$, respectively, and also residual weight $\left(\mathrm{R}_{\mathrm{w}}\right)$ at $600^{\circ} \mathrm{C}$ all have been tabulated in Table 3 .

\begin{tabular}{|l|l|l|l|l|l|}
\hline & $\mathbf{T}_{5 \%}\left({ }^{\circ} \mathbf{C}\right)$ & $\mathbf{T}_{10 \%}\left({ }^{\circ} \mathbf{C}\right)$ & $\mathbf{T}_{25 \%}\left({ }^{\circ} \mathbf{C}\right)$ & $\mathbf{T}_{50 \%}\left({ }^{\circ} \mathbf{C}\right)$ & $\mathbf{R}_{\mathrm{W}}$ (wt. \%) \\
\hline P1 & 364 & 413 & 522.21 & 580.37 & 24.5 \\
\hline
\end{tabular}




\begin{tabular}{|l|l|l|l|l|l|}
\hline P2 & 332 & 432 & 554.76 & 597.13 & 47.92 \\
\hline P3 & 352 & 426 & 518.14 & 593.5 & 43.5 \\
\hline
\end{tabular}

Table 3: Thermal stability parameters extracted from TGA thermograms.

It is seen in Figure 3 that there are three min mass loss steps in degradation process of all the PAEKs. The first small weight loss ranged from $110^{\circ} \mathrm{C}$ to $180^{\circ} \mathrm{C}$ can be attributed to the loss of residual moisture and solvent. The second step, starting at about $350-370^{\circ} \mathrm{C}$ attributes to the degradation of the alkyl group attached to the Nitrogen atom or could be due to the decomposition of the oligomers at lower temperatures or the reaction between the terminal hydroxyl and terminal fluorine groups at relatively high temperatures [38]. The third weight loss step started at around $530^{\circ} \mathrm{C}, 560^{\circ} \mathrm{C}$ and $550^{\circ} \mathrm{C}$ for $\mathrm{P} 1$, $\mathrm{P} 2$ and $\mathrm{P} 3$, respectively can be ascribed to the decomposition of the polymer backbone. Furthermore, the char yields at $600^{\circ} \mathrm{C}$ are $47.92 \%$ for P2, $43.5 \%$ for $\mathrm{P} 3$ and $24.5 \%$ in the case of P1. Therefore, it can be concluded that generally $\mathrm{P} 2$ possesses the best thermal stability among these synthesized PAEKs. Differences in thermal performance of polymers can be explained based on differences in chemical structure of monomers. P2, because of having two aromatic fused rings has more potential to sustain against temperature raise and its ability in char formation is more than P1 and P3. Also, the differences in the case of $\mathrm{P} 1$ and $\mathrm{P} 3$ can be attributed to the position of bonds on repeating unit of polymer, i.e., para or meta.
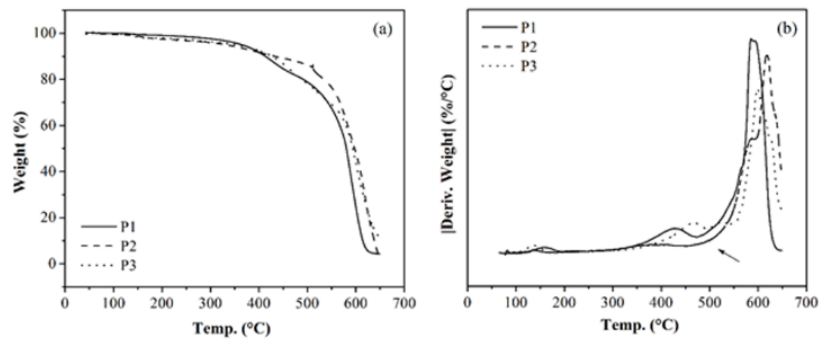

Figure 3: TGA thermo grams of the different PAEKs in air.

The DSC curves of synthesized polymers are depicted in Figure 4. In all the samples a small endothermic peak is recognized at around $100^{\circ} \mathrm{C}$ which attribute to the relaxation process of polymer segments. Glass transition temperatures $\left(\mathrm{T}_{\mathrm{g}}\right)$ of these polymers were determined equal to 105,88 and $125^{\circ} \mathrm{C}$ for $\mathrm{P} 1, \mathrm{P} 2$ and $\mathrm{P} 3$, respectively. Furthermore, the presence of no melting endotherms in the DSC thermo gram is an indicative of amorphous nature of synthesized PAEKs. The exothermic peak which is seen in the case of $\mathrm{P} 2$ relates to some processes similar to cold crystallization phenomenon. In P2, since the molecular structure of repeating unit is more rigid than P1 and P3 therefore in the cooling cycle these chains do not have enough time to enter into more ordered phases, while during heating they enter to order structures and hence show exothermic peak. It should be noted that as mentioned earlier all the three polymers have no melting peaks therefore the exothermic peak of $\mathrm{P} 2$ can be not attributed to the cold crystallization and it only relates to some exothermic transitions originating from some enhancement in extent ordered structures.

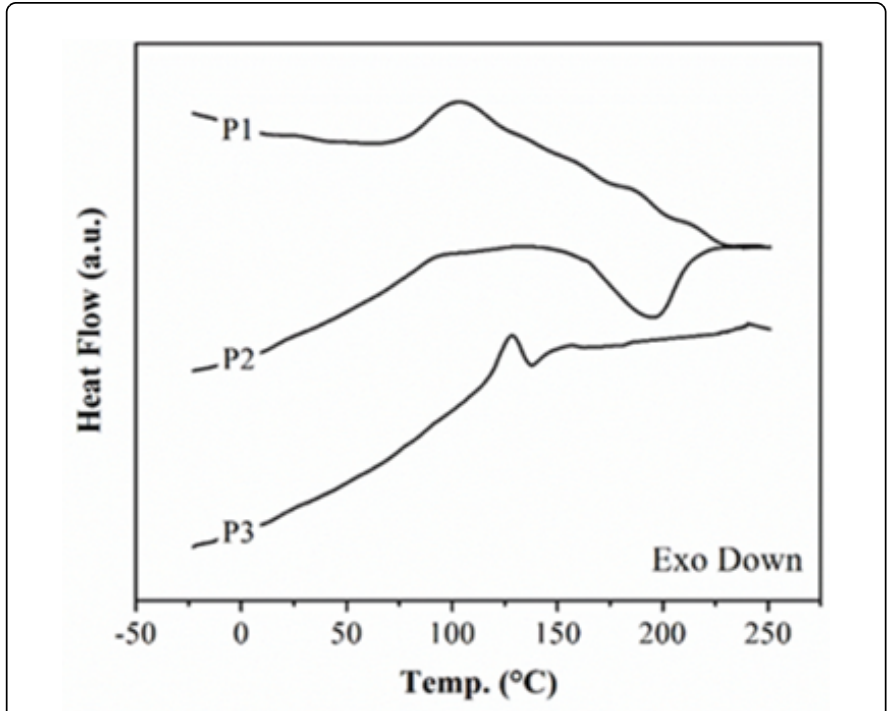

Figure 4: DSC thermo gram of P3 in N2 (Heating cycle).

\section{Conclusion}

A novel series of PAEKs containing 9-ethylcarbazole groups in their main chain were synthesized by reaction between three different bisphenols with the produced new difluoride monomer. The formation of PAEKs was confirmed using spectroscopic techniques of FTIR and 1HNMR. Later on, the properties of synthesized PAEKs were analyzed in terms of solubility, viscosity and thermal properties. The inherent viscosities of PAEKs were estimated in the range of $0.32-0.53 \mathrm{dl} / \mathrm{g}$ for solutions of $0.1 \mathrm{~g} / \mathrm{dl}$ in DMAc at $25^{\circ} \mathrm{C}$. It was indicated that all the synthesized PAEKs unlike the conventional PAEKs, were soluble or partially soluble in the common aprotic organic solvents such as DMAc, NMP, DMF and DMSO and also in concentrated $\mathrm{H}_{2} \mathrm{SO}_{4}$. TGA traces of the novel PAEKs showed a minor mass loss of about 10 wt. \% until $400^{\circ} \mathrm{C}$ which is an indication of considerably high thermal stability of these polymers. By comparing mass loss values of these polymers at same temperatures and also considering their char yield at $600^{\circ} \mathrm{C}$, it was concluded that $\mathrm{P} 2$ possesses the best thermal stability among the all novel PAEKs. Higher glass transition was determined to P3 in DSC experiment. Differences in thermal properties including glass transition and thermal stability of polymers were explained based on structural differences of monomers and their para/metapositional isomerism. Moreover, results of DSC experiment showed that there are no crystalline structures in the synthesized PAEKs.

\section{Acknowledgment}

We would like to acknowledge the help and support from Golestan University which helped us publish this research.

\section{References}

1. Cassidy PE (1980) Thermally stable polymers. New York, Marcel Dekker.

2. Cotter RJ (1995) Engineering plastics: a handbook of polyarylethers. Taylor \& Francis (UK).

3. Rabilloud G (1999) High-performance polymers: chemistry and applications. Editions Technic. 
4. Johnson RN, Farnham AG, Clendinning RA, Hale WF, Merriam CN (1967) Synthesis of aromatic polyketones via soluble precursors derived from bis( $\alpha$ - aminonitrile)s. Journal of Polymer Science, Part A-1: Polymer Chemistry 52: 2375-2398.

5. Maiti S, Mandal BK (1986) Aromatic polyethers by nucleophilic displacement polymerization. Progress in Polymer Science 12: 111-153.

6. Jayakannan M, Ramakrishnan S (2001) Recent developments in poyrther synthesis. Macromolecular Rapid Communications 22: 1463-1473.

7. Moroz AA, Shvartsberg MS (1947) The Ullman rather condensation. Russian Chemical Reviews 43: 679-689.

8. Hay AS (1999) Poly(phenylene oxides)s and poly(arylene ether)s derived from 2,6 diarylphenols. Progress in Polymer Science 24: 45-80.

9. Brunel R, Marestin C, Martin V, Mercier R, Schiets F (2008) Assisted Microwave Synthesis of High Molecular Weight Poly(Aryletherketone)s. High Performance Polymers 20: 185-207.

10. Attwood T, Dawson P, Freeman J, Hoy L, Rose J, et al. (1981) Synthesis and Properties of Polyaryletherketones. Polymer 22: 1096-1103.

11. Ohno M, Takata T, Endo T (1995) Synthesis of a novel naphthalene-based poly (arylene ether-ketone) by polycondensation of 1,5-bis (4fluorobenzoyl)-2,6-dimethylnaphthalene with bisphenol A. Journal of Polymer Science Part A: Polymer Chemistry 33: 2647-2655.

12. Ji XL, Yu DH, Zhang WJ, Wu ZW (1997) The multiple melting behaviour of immiscible poly (ether ether ketone)/poly(ether diphenyl ether ketone) blend. Polymer 38: 3501-3504.

13. Ji XL, Ji ZW, Wu ZW (1996) Miscibility of poly(ether ether ketone)/ poly(ether diphenyl ether ketone) blends. Polymer 37: 4205-4208.

14. Cao J, Wu Z, Liu J, Kitayama T, Hatada K (1996) Crystallization behaviour of poly(ether ether ketone)/poly(ether sulfone) block copolymer. Polymer 37: 4579-4584.

15. Rao VL (1995) Journal of Macromolecular Science, Part C: Polymer Reviews 35: 661-712.

16. Olabisi O, Adewale K (1997) Handbook of thermoplastics. London, CRC press.

17. Wallace GG, Teasdale PR, Spinks GM, Kane-Maguire LA (2008) London, CRC press.

18. Grazulevicius JV, Strohriegl P, Pielichowski J, Pielichowski K (2003) Carbazole-containing polymers: synthesis, properties and applications. Progress in Polymer Science 28: 1297-1353.

19. Klionsky DJ, Abdalla FC, Abeliovich H, Abraham RT, Acevedo-Arozena A, et al. (2012) Autophagy 8: 445-544.

20. Blouin N, Leclerc M (2008) Poly (2,7-carbazole)s: Structure-Property Relationships. Accounts of Chemical Research 41: 1110-1119.

21. Watanabe M, Nishiyama M, Yamamoto T, Koie Y (2000) Palladium/P(t$\mathrm{Bu}$ )3-catalyzed synthesis of $\mathrm{N}$-aryl azoles and application to the synthesis of 4,4',4"-tris(N-azolyl)triphenylamines. Tetrahedron Letters 41: 481-483.

22. Chen JP, Labarthet FL, Natansohn A, Rochon P (1999) Highly Stable Optically Induced Birefringence and Holographic Surface Gratings on a New Azocarbazole-Based Polyimide. Macromolecules 32: 8572-8579.

23. Bubniene G, Malinauskas T, Stanisauskaite A, Jankauskas V, Getautis V (2009) Synthesis of new hole-transporting molecular glasses with pendant carbazolyl-based hydrazone moieties. Synthetic Metals 159: 1695-1700.
24. Koyuncu FB, Koyuncu S, Ozdemir E (2011) A new donor-acceptor carbazole derivative: Electrochemical polymerization and photo-induced charge transfer properties. Synthetic Metals 161: 1005-1013.

25. Ghaemy M, Nasr FH, Alizadeh R, Taghavi M (2012) Synthesis and characterization of novel photoactive, thermally stable, and organosoluble polymers based on carbazole and imidazole derivatives in the mainchain. Macromolecular Research 20: 614-622.

26. Satpathi H, Ghosh A, Komber H, Banerjee S, Voit B (2011) Synthesis and characterization of new semifluorinated linear and hyperbranched poly(arylene ether phosphine oxide)s through B2 + A2 and AB2 approaches. European Polymer Journal 47: 196-207.

27. Siove A, Adès D (2004) Synthesis by oxidative polymerization with $\mathrm{FeCl} 3$ of a fully aromatic twisted poly (3,6-carbazole) with a blue-violet luminescence. Polymer 45: 4045-4049.

28. Iraqi A, Wataru I (2004) 3,6-linked 9-alkyl-9H-carbazole main-chain polymers: Preparation and properties. Journal of Polymer Sci Part A: Polymer Chemistry 42: 6041-6051.

29. Zhang ZB, Fujiki M, Motonaga M, Nakashima H, Torimitsu K, et al. (2002) Chiroptical Properties of Poly\{3,4-bis[(S)-2methyloctyl]thiophene\}. Macromolecules 35: 941-944.

30. Grigalevicius S, Lideikis E, Grazulevicius J, Gaidelis V, Antulis J, et al. (2002) Synthesis and properties of the polymers containing 3,3'dicarbazyl units in the main chain and their model compounds. Polymer 43: 5693-5697.

31. Chauhan SS, Yi H, Iraqi A (2008) N-Aryl 2,7-Linked Caracole Polymers and Copolymers with Fluorine Protecting Groups: A New Class of Blue Emitting Polymers for LED Applications. Molecular Crystals and Liquid Crystals 497: 129-141.

32. Výprachtický D, Kmínek I, Pokorná V, Cimrová V (2012) Efficient synthesis of N-alkyl-2,7 dihalocarbazoles by simultaneous carbazole ring closure and N-alkylation. Tetrahedron 68: 5075-5080.

33. Morrison R, Boyd R (1973) Organic Chemistry. 3rd edn., Boston, Allyn and Bacon.

34. Osano K, Das S, Turner SR (2009) Synthesis and characterization of cyclohexyl-containing poly(ether ketone sulfone)s. Polymer 50: 1144-1149.

35. Sharapov DS, Shaposhnikova VV, Salazkin SN, Mamedova IA, Dubrovina LV, et al. (2004) Synthesis of poly(arylene ether ketones) with terminal phenolic groups. Russian Chemical Bulletin 53: 2041-2044.

36. Niu Y, Zhu X, Liu L, Zhang Y, Wang G, et al. (2006) Synthesis and characterization of poly(aryl ether ketone) with trifluoromethylsubstituted benzene in the side chain. Reactive and Functional Polymers 66: 559-566.

37. Grigoras M, Antonoaia NC (2005) Synthesis and characterization of some carbazole-based imine polymers. European Polymer Journal 41: 1079-1089.

38. Zhou Y, Qing FL (2008) Novel fluorinated poly (aryl ether)s derived from 1,2-bis(4-(4-fluorobenzoyl)phenoxy)-hexafluorocyclobutane. Journal of Fluorine Chemistry 129: 498-502. 